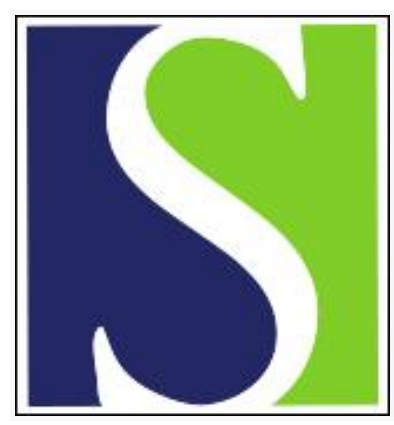

Scand J Work Environ Health 1996;22(5):339-345

https://doi.org/10.5271/sjweh.151

Issue date: Oct 1996

Brain tumor risk in offspring of men occupationally exposed to electric and magnetic fields

by Wilkins JR III, Wellage LC

Key terms: adverse effect; brain neoplasm; electromagnetic fields; epidemiology; occupational exposure

This article in PubMed: www.ncbi.nlm.nih.gov/pubmed/8923606

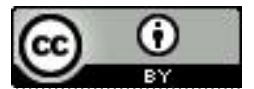




\title{
Brain tumor risk in offspring of men occupationally exposed to electric and magnetic fields
}

\author{
by JR Wilkins III, DrPH, ${ }^{1}$ Lynn C Wellage, MS ${ }^{1}$
}

\begin{abstract}
Wilkins JR III, Wellage LC. Brain tumor risk in offspring of men occupationally exposed to electric and magnetic fields. Scand J Work Environ Health 1996;22:339-45.

Objectives The purpose of the study was to address the possible associations between the occupational exposure of men to electromagnetic fields (EMF) and the risk of childhood brain tumors in offspring by reanalyzing case-referent interview data from a study of environmental factors and childhood brain tumors conducted by one of the authors and first reported in 1990.

Methods Analyses of the case-referent data were limited to the 94 cases and 166 individually-matched referents for whom data on the biological fathers were available. Paternal exposure to occupational EMF was inferred from a list of job titles compiled for that purpose. Mantel-Haenszel odds ratios (OR) for individually matched cases and referents were estimated for different definitions of exposure.

Results The findings suggested at best very small increases in risk for jobs associated with the occupational EMF exposure of fathers during the one-year period prior to conception, the OR values ranging from 1.12 to 1.31. Notably elevated $O R$ values were, however, found in association with any paternal welding in the one-year preconception period (OR 3.8, 95\% confidence interval 0.95-15.55).

Conclusions The results of reanalysis indicate that preconceptional paternal occupational exposure to EMF is at best only weakly associated with a risk of childhood brain tumors. However, the findings for paternal welding are somewhat intriguing since relatively strong EMF have been measured in association with welding. Further study of welding as a potential risk factor is required since welders may be exposed to a wide range of toxic agents in addition to EMF.
\end{abstract}

Key terms brain neoplasms; electromagnetic fields, adverse effects; neoplasms, epidemiology; occupational exposure.

Each year in the United States approximately 1200 new cases of primary tumors of the central nervous system (CNS) are diagnosed among children less than 15 years of age (1). The incidence varies with age, gender, and race but is approximately 2.5 per 100000 children per year, making CNS tumors second only to leukemia in childhood cancer incidence.

Despite continued research, the etiology of childhood CNS tumors remains unclear. Some attention has focused on parental occupation, with the generally positive findings from early studies concerning "hydrocarbonrelated" occupations not subsequently confirmed by most later studies (2-5). A still smaller number of studies (6-11) has examined the question of parental (usually paternal) occupational exposure to electromagnetic fields and risk of childhood nervous system cancer, specifically neuroblastoma $(6,10,11)$ and brain tumors $(7-9)$.
In the Nasca et al (7) case-referent interview study on childhood brain tumors, odds ratios (OR) for paternal employment in jobs presumed to involve exposure to electromagnetic fields (at the time of birth) were modestly elevated (narrow-definition OR 1.7, broad-definition OR 1.6). In the case-referent study conducted by Johnson \& Spitz (9) with the use of birth and death certificates, paternal employment in industries linked with electromagnetic field exposure (at the time of birth) was found to be associated with a similar increase in the risk of childhood brain tumors in offspring (OR 1.6). In their analysis of paternal occupation, case fathers were more likely to have been electricians (OR 3.5) and much more likely to have been construction electricians (OR 10.1). Although their case-referent interview study was not designed to test the electromagnetic field hypothesis specifically, Wilkins \& Sinks (8) found that the OR values

1 Division of Epidemiology and Biometrics, School of Public Health, The Ohio State University, Columbus, OH, United States.

Reprint requests to: Dr JR Wilkins III, Division of Epidemiology and Biometrics, School of Public Health, Ohio State University, 320 West 10th Avenue, Columbus, Ohio 43210, USA. 
for paternal employment in three periods (preconception, pregnancy, postnatal) ranged from 2.0 to 3.2 for job cluster 3 of Hsieh et al (12). This job cluster represents a grouping of jobs linked by a job-exposure matrix to the potential for heavy exposure to electromagnetic fields (13).

It could be readily argued that the evidence taken as a whole regarding the association between childhood brain tumors and parental employment in occupations or industries involving electromagnetic field exposure is not compelling. In our opinion, however, the findings in this area to date are not sufficiently persuasive to conclude that there is no real association (hence the rationale for conducting a reanalysis of case-referent data).

\section{Subjects and methods}

\section{Case and referent selection}

Data collection procedures have been detailed elsewhere (8) but are briefly summarized below.

Cases were identified through the Columbus Children's Hospital Tumor Registry. Patients less than 20 years of age with CNS tumors [code 191 of the International Classification of Diseases, ninth revision (ICD9)], diagnosed during the eight-year period 1 January 1975 through 31 December 1982, were identified for possible inclusion. Permission to contact the family was sought and obtained from the family physician prior to any interviewing.

Random-digit dialing was used to select referents from the 48-county referral area of the Columbus Children's Hospital Tumor Registry. As previously described (14), the telephone exchange was not used as a matching factor because the selection of referents on any close geographic or residential basis might have resulted in overmatching on parental occupation. The referents were cancer-free biological children of the household residents and were individually matched to cases by gender, race, year of birth, and survival up to the age of the case's diagnosis. Attempts were made to obtain two referents for each case.

Table 1. Reasons for the exclusion of potential cases.

\begin{tabular}{lccc}
\hline Reasons for exclusion & $\begin{array}{c}\text { Number } \\
\text { excluded }\end{array}$ & $\begin{array}{c}\text { Percentage } \\
\text { of the } \\
59 \text { excluded }\end{array}$ & $\begin{array}{c}\text { Percentage } \\
\text { of the } \\
153 \text { cases } \\
\text { identified }\end{array}$ \\
\hline Physician refusal & 7 & 11.8 & 4.6 \\
Parental refusal & 18 & 30.5 & 11.8 \\
No contact made & 14 & 23.7 & 9.2 \\
No control identified & 3 & 5.1 & 2.0 \\
Not in population at risk & 2 & 3.4 & 1.3 \\
Occupational data unavailable & 14 & 23.7 & 9.2 \\
Child not home since birth & 1 & 1.7 & 0.6 \\
\hline Total & 59 & 99.9 & 38.7 \\
\hline
\end{tabular}

The telephone interview elicited information on a wide range of hypothesized risk factors for childhood brain tumors (8). When possible, the biological parents of each case and referent were interviewed separately to obtain the occupational history data. In general the information pertained specifically to the following periods: the one-year period prior to conception, the pregnancy period, and the period of time from birth to diagnosis.

Of the 153 cases initially identified, 94 were eligible for inclusion in the analysis reported in this communication (table 1). Sixty-seven percent of the 94 cases were male children; this percentage is consistent with national data that demonstrate a higher frequency of childhood brain tumors among males (1). Furthermore, the frequency of tumor types was found to be comparable to that described for white children in the SEER (surveillance epidemiology, and end results) data (1). Slightly more than half of the cases were diagnosed with astrocytoma $(29.8 \%$ ) or medulloblastoma (26.6\%). In the SEER data these tumor types constitute $39 \%$ and $22 \%$ of the cases, respectively. As in the national data, glioma, ependymoma, and glioblastoma were found to be the next most frequently occurring tumor types.

\section{Classification of exposure}

In the past, the classification of occupational electromagnetic field exposure has largely been an intuitive process (15). Exposure has been inferred from a job title or a job description, or expert opinion has been used. Since a classification scheme based on direct measurements would likely represent an improvement over previous approaches, the results of published dosimetry studies were reviewed with the intent of constructing a better exposure classification scheme. Although most data in the open literature were judged to be inadequate for this purpose, results of the Bowman et al (16) dosimetry studies of the "electrical" occupations suggested by Milham (17) were used to modify the classification scheme proposed by Loomis \& Savitz (18). (See table 2.) Specifically, this modification consisted of adding the following three census bureau occupational codes: 683 (electronics assemblers), 856 (fork-lift operators), and 783 (welders).

Coding of the occupational data [according to the 1980 census bureau codes (19)] was performed blindly as to case-referent status. All relevant information obtained during the interview was used in assigning the appropriate code: the job title; the description of duties, activities, responsibilities; and any data reported in response to an open-ended question about workplace exposures. In general, if any evidence of electromagnetic field exposure was present, the individual was classified with a code which would indicate occupational electromagnetic field exposure. For example, an individual 
whose self-reported job title was "laborer," and whose job description read "built billboards, painted, welded," was given the code 783 for welders. Because welders have relatively high mean exposures to electromagnetic fields (20), welders were selected a priori for a separate analysis.

All the jobs held by the fathers during the pregnancy period and the year prior to conception were coded, but only one job per father was used in the analysis for each period. In circumstances where a father reported multiple jobs during a single period, the following rules were observed. If one of the codes in table 2 was present, it was assigned and the others were ignored. If two or more codes in table 2 were present, and one of them was 783 (welding), then the job given code 783 was used in the analysis. If two or more codes in table 2 were present, and none was equal to 783 , then the code for the job of greater duration associated with electromagnetic field exposure was used. If none of the jobs were assigned a code associated with electromagnetic field exposure, then the job of greater duration was used. If the jobs were of equal duration, then the code for the first chronological job was selected. If two jobs were held simultaneously, then the job with the greater number of hours worked per week was used.

The unexposed reference group was defined as all occupations not given in table 2 , including unemployed persons. Thus when welding exposure was examined, the cases and referents whose fathers were employed in nonwelding occupations with presumed electromagnetic field exposure were excluded from the analysis.

The two periods of interest were treated separately, with the number of months employed in the job with presumed electromagnetic field exposure used in an attempt to refine the exposure measure. For the pregnancy period, the following two duration-dependent definitions of exposure were applied: father held job at any time during the pregnancy period and father held job for five or more months during the pregnancy period.

For the preconception period, the following exposure definitions were used: father held job any time during the year prior to conception, and father held job any time during the $75-\mathrm{d}$ period immediately preceding conception. The last definition was an attempt to examine the period of spermatogenesis relevant to the index pregnancy (21).

\section{Statistical methods}

The purpose of our analysis was to evaluate the hypothesized association between the risk of childhood brain tumor and a specific group of parental (paternal) occupations. To this end, analyses were limited to the 94 cases and 166 referents for whom data on the biological fathers were available. Mantel-Haenszel estimates of the odds ratio $(\mathrm{OR})$ for cases individually matched to a variable
Table 2. Occupations with presumed exposure to electromagnetic fields and associated census codes. ${ }^{2}$

\begin{tabular}{ll}
\hline $\begin{array}{l}\text { Census } \\
\text { code }\end{array}$ & Occupation \\
\hline 055 & Electrical and electronic engineers \\
213 & Electrical and electronic technicians \\
228 & Broadcast equipment operators \\
523 & Electronic repair, communication and industrial equipment \\
525 & Data processing equipment repairers \\
526 & Household appliance and power tool repairers \\
527 & Telephone line installers and repairers \\
529 & Telephone installers and repairers \\
533 & Miscellaneous electrical and electronic equipment repairers \\
555 & Supervisors, electricians and power installers and repairers \\
575 & Electricians \\
576 & Electrician apprentices \\
577 & Electric power installers and repairers \\
683 & Electronic assemblers and other electric equipment assemblers \\
695 & Power plant operators \\
773 & Motion picture projectionists \\
783 & Welders \\
856 & Fork-lift operators \\
\hline
\end{tabular}

a Modified version of classification system described by Loomis \& Savitz (18).

number of referents were calculated as effect measures (22). Ninety-five percent confidence intervals (95\% CI), based on the method described by Robins et al (23), were estimated with StatXact software (24). The evaluation of potential confounding was restricted by a limited sample size, relatively uncommon exposures, and few known risk factors for childhood brain tumors.

The number of referents for the preconception and prenatal periods differed slightly due to missing occupational data. For the preconception period, 166 referents were matched to the 94 cases as 72 triplets and 22 pairs. For the pregnancy period, 167 referents were matched to the same 94 cases as 73 triplets and 21 pairs.

\section{Results}

\section{Inferred occupational exposure to electromagnetic fields}

The odds ratios and $95 \%$ confidence intervals for paternal employment in jobs associated with occupational exposure to electromagnetic fields are given in table 3 . The three OR values for the preconception period varied from 1.12 to 1.31 ; they all have confidence limits with lower bounds in the $0.4-0.6$ range and upper bounds in the 2.8-3.0 range. No increase in risk was found for paternal employment (defined two ways) during the pregnancy period.

\section{Any job involving welding (broad definition)}

For paternal welding anytime during the preconception period (and for welding anytime during the $75 \mathrm{~d}$ prior to conception), the OR values were notably elevated, as shown in table 4 (OR 3.83, 95\% Cl 0.95-15.55). Restricting the definition of exposure to include only the 
Table 3. Odds ratios (OR) and 95\% confidence intervals (95\% Cl) for paternal employment in occupations with presumed electromagnetic field exposure.

\begin{tabular}{|c|c|c|c|}
\hline Time period & $\begin{array}{l}\text { Number of } \\
\text { exposed } \\
\text { case fathers }\end{array}$ & $O R^{a}$ & $95 \% \mathrm{Cl}^{b}$ \\
\hline \multicolumn{4}{|l|}{ Preconception } \\
\hline $\begin{array}{l}\text { Any employment during } \\
\text { time period }\end{array}$ & 11 & 1.31 & $0.58-2.98$ \\
\hline $\begin{array}{l}\text { Employment for } \geq 7 \text { months } \\
\text { during time period }\end{array}$ & 8 & 1.12 & $0.44-2.83$ \\
\hline $\begin{array}{l}\text { Employment during } 75 \mathrm{~d} \text { prior } \\
\text { to conception }\end{array}$ & 10 & 1.26 & $0.53-2.98$ \\
\hline \multicolumn{4}{|l|}{ Pregnancy } \\
\hline Any employment during time period & 9 & 1.03 & $0.45-2.39$ \\
\hline $\begin{array}{l}\text { Employment for } \geq 5 \text { months during } \\
\text { time period }\end{array}$ & 8 & 1.04 & $0.42-2.54$ \\
\hline
\end{tabular}

a Mantel-Haenszel estimates for matched data (22).

b Variance estimated using the method of Robins et al (23).

Table 4. Odds ratios (OR) and $95 \%$ confidence intervals (95\% Cl) for paternal employment in occupations involving welding. ${ }^{\text {a }}$

\begin{tabular}{|c|c|c|c|}
\hline Time period & $\begin{array}{l}\text { Number of } \\
\text { exposed } \\
\text { case fathers }\end{array}$ & $\mathrm{OR}^{\mathrm{b}}$ & $95 \% \mathrm{Cl}^{\circ}$ \\
\hline \multicolumn{4}{|l|}{ Preconception } \\
\hline $\begin{array}{l}\text { Any welding-related employment } \\
\text { during time period }\end{array}$ & 6 & 3.83 & $0.95-15.55$ \\
\hline $\begin{array}{l}\text { Welding-related employment } \\
\text { for } \geq 7 \text { months during time period }\end{array}$ & $5-$ & 3.17 & $0.75-13.44$ \\
\hline $\begin{array}{l}\text { Welding-related employment } \\
\text { during } 75 \mathrm{~d} \text { prior to conception }\end{array}$ & 6 & 3.83 & $0.95-15.55$ \\
\hline Only welding & 3 & 1.75 & $0.23-13.21$ \\
\hline \multicolumn{4}{|l|}{ Pregnancy } \\
\hline $\begin{array}{l}\text { Any welding-related employment } \\
\text { during time period }\end{array}$ & 5 & 2.50 & $0.67-9.31$ \\
\hline $\begin{array}{l}\text { Welding-related employment } \\
\geq 5 \text { months during time period }\end{array}$ & 5 & 3.33 & $0.80-13.95$ \\
\hline Only welding & 2 & 1.00 & $0.09-11.03$ \\
\hline
\end{tabular}

a Exposed group includes all fathers who reported welding as a sole job task or as one of several job tasks.

- Mantel-Haenszel estimates for matched data (22).

c Variance estimated using the method of Robins et al (23).

fathers employed in a welding-related job for at least seven months during the preconception period decreased the OR slightly (OR 3.17, 95\% CI 0.75-13.44). Every father who reported welding during the preconception period reported to have welded during the $75 \mathrm{~d}$ prior to conception.

As is also shown in table 4 , the OR for any welding exposure during the pregnancy period was elevated (OR $2.50,95 \%$ CI $0.67-9.31$ ), but more modestly so than for the preconception period. Restricting the definition of welding exposure to five or more months during the pregnancy period increased the OR to $3.33(95 \% \mathrm{CI}$ $0.80-13.95)$.

There were no striking gender, age, or tumor-type patterns evident among the cases whose fathers reported job-related welding; several tumor types and a variety of ages were represented.

\section{Paternal welding as only job task (narrow definition)}

Table 4 also gives OR values and $95 \%$ confidence intervals for paternal employment using the narrow definition of welding exposure (welding was the sole reported job task). The OR for the preconception period was elevated (OR 1.75, 95\% CI 0.23-13.31), but much more modestly than when the broad definition was used. Applying the narrow definition gave only three case fathers in the preconception period, and, not surprisingly, the OR had a wide confidence interval. No increase in risk was found for the pregnancy period (only two case fathers satisfied the exposure definition).

\section{Time periods}

Although the two time periods were examined separate$1 y$, differences in the paternal employment patterns between the two were small, and it was therefore difficult to delineate risk by time period. For example, of the nine fathers who reported job-related welding anytime during the preconception period, eight also welded during the pregnancy period. Likewise, of the nine fathers who welded during the pregnancy period, eight also welded during the preconception period. Thus a total of $10 \mathrm{fa}-$ thers had jobs involving welding, of whom eight welded during both time periods.

\section{Potential confounders}

When potential confounders in our data were examined, attention focused on the analysis of paternal welding exposure since the analysis for inferred exposure to electromagnetic fields yielded weak evidence at best for a positive association and none of the potential confounders would be considered protective. In all the analyses, the potential confounder was treated as a dichotomous variable, and no attempt was made to quantify the degree of exposure to the potential confounder. Overall, there was little evidence for confounding from maternal or childhood exposure to $\mathrm{X}$ rays, parental smoking, or household pesticide use. Furthermore, controlling for the potential confounder did not substantially alter the OR for paternal exposure to welding.

\section{Discussion}

The results - that the preconception exposure of fathers to occupational electromagnetic fields was found at best to be only weakly associated with increased risk, while a much stronger association was seen for paternal welding - are potentially affected by several possible weaknesses and biases. The discussion that follows focuses on 
the weaknesses that complicate the interpretation and perhaps compromise the informativeness of the findings.

Any associations found in any study can be the result of chance, but particular attention must be given to this possibility in the context of the current analysis. Although relatively few tests were conducted, the reported results represent a reanalysis of data on which numerous analyses have already been performed. It must also be acknowledged that the objectives of the initial data collection effort did not include a specific focus on the question of parental electromagnetic field exposure and childhood brain tumor risk. Furthermore, the small sample size (and the small number of fathers classified as exposed) enhances the possibility that the reported results can be explained by chance.

Epidemiologic studies of health effects related to electromagnetic field are particularly vulnerable to exposure misclassification bias. Investigators conducting the early studies of occupational exposure to electromagnetic fields relied heavily on job title (eg, a job title with "electric" was automatically included). In past studies (and in the current one), electricians were classified as exposed to electromagnetic fields despite the fact that most nonindustrial electricians work in situations where the power is turned off. Furthermore, a single job title is unlikely to capture adequately the considerable variability in occupational exposure to electromagnetic fields (25), which derives from two sources. First, there is the variability within a broadly defined occupation, which is evident from dosimetry data (16). Second, variability in occupational electromagnetic field exposure exists among workers in the same occupation and work environment. For example, power station operators working in generating stations have a geometric mean exposure of $6.0 \times 10^{-7} \mathrm{~T}$, but the range for this category extends from $0.1 \times 10^{-7}$ to $118 \times 10^{-7} \mathrm{~T}(16)$. Thus the withinoccupation variability in electromagnetic field exposure precludes error-free classification of workers on the basis of job title alone. In the current study, information on job tasks, responsibilities, and exposures was also used in determining exposure status. Although this addition probably represents an improvement, the interview was not conducted with the current hypothesis in mind, and thus particularly pertinent information concerning each work environment was not obtained.

In case-referent interview studies, the possibility exists that cases are more (or less) likely to report exposure(s) than referents, even if overall (average) exposure levels are similar in both groups. This concern intensifies if the cases (or case parents) are more (or less) aware of the study hypothesis than the referents (or reference parents) $(26,27)$. The hypothesis for the current analysis was not, however, widely publicized at the time the interviewing took place, and the interviewers were unaware of it as a potential study hypothesis. Thus it seems unlikely that the case fathers would have been more likely to report occupations associated with electromagnetic fields or welding because of specific beliefs concerning the effects of such exposures.

Boyle et al (see their table 4) recently reported on the validity of occupational exposure data obtained from proxy respondents (28). Using self-reports as the standard, they found that proxy interviews (from a spouse or other knowledgeable surrogate) produced poor sensitivities, ranging from $0 \%$ to $52 \%$ for questions about 13 specific occupational exposures (the average of the 13 sensitivities was approximately $30 \%$ ). This finding is relevant to the current analysis since it was not possible to obtain occupational data for each father by personal self-report. Seventy-nine percent of the occupational data for the case fathers was from self-report compared with $71 \%$ for the reference fathers. The small size of this discrepancy suggests that it is unlikely that this potential source of bias was solely responsible for the elevated $O R$ observed for the welders.

In evaluations of the effect of confounding in this study, a distinction should be made between occupational and nonoccupational confounders, although age, gender, and race are the only factors consistently associated with the risk differences (29-31). Several potential nonoccupational confounders were considered (parental smoking, maternal and child exposure to $\mathrm{X}$ rays, and use of domestic pesticides), but were found not to be confounders in our data. Although it is possible that some unidentified nonoccupational confounder could explain the elevated OR associated with welding, the absence of increased risk for other occupations with presumed exposure to electromagnetic fields argues against this possibility. Welders are similar to these other occupational groups with respect to socioeconomic status, and thus it seems reasonable to expect that such workers as welders, electricians, power plant operators, and telephone linemen have, on the average, similar income levels, educational backgrounds, and health behaviors. If some unidentified confounder was responsible for the elevated OR values found for the welders, this same confounder would be expected to elevate the OR associated with these other occupational groups. The OR values associated with these other groups were not elevated, and thus the argument for an unidentified confounder of a nonoccupational nature is weak. It must however also be acknowledged that other sources of electromagnetic field exposure were not considered (eg, home or residential exposures and exposures resulting from the use of electrical appliances such as electric blankets).

Occupational exposure to electromagnetic fields could be confounded by other occupational exposures [as based on a previous analysis of the same case-referent data (8); this concern would pertain only to fathers, not mothers]. The elevated OR associated with welding 
could be attributable to electromagnetic field exposure or to some other chemical or physical exposure common to welding.

Whether there is a causal relationship between paternal exposure to welding and childhood brain tumor is in our opinion deserving of more attention. Although one plausible explanation for the elevated OR values associated with paternal welding found in this study is a combination of chance and bias, it is also true that the evidence concerning the potential reproductive health effects associated with welding is intriguing. There is indirect evidence that welding can affect sperm cell viability (32-34) and thus this evidence invites speculation about possible DNA damage. Since welding is associated with higher than average exposure to electromagnetic fields, it should be noted that electromagnetic fields have stimulated biological activity in several biological systems. For example, electromagnetic fields can affect circadian rhythms, calcium ion transport across cell membranes, and nervous system function (35). Welding is also associated with an array of chemical exposures and, importantly, heat, which can adversely affect spermatogenesis (36). It could be argued that these exposures are the relevant ones with respect to paternal electromagnetic field exposure and cancer risk in offspring.

Future research efforts should focus on the careful characterization of welding exposure. In addition, since research suggests that welding exposure may be associated with several different health effects, cohorts of welders and referents might be compared for a variety of reproductive outcomes, including multigenerational effects.

\section{Acknowledgments}

The authors gratefully acknowledge the assistance of Dr Melvin L Moeschberger and the staff of the School of Public Health's Biometrics Laboratory. Appreciation is also extended to Patricia A Price and Lynn Higginbotham for the preparation of the manuscript. In addition, the authors thank Dr David Savitz for his comments on an earlier version of this article.

The study was supported in part by grants from the Bremer Foundation and the Ohio Department of Health.

\section{References}

1. Young JL, Ries LG, Silverberg E, Horm JW, Miller RW. Cancer incidence, survival, and mortality for children younger than age 15 years. Cancer 1986;58:598-602.

2. O'Leary LM, Hicks AM, Peters JM, London S. Parental occu- pational exposures and risk of childhood cancer: a review. Am J Ind Med 1991;20:17-35.

3. Arundel SE, Kinnier-Wilson LM. Parental occupations and cancer: a review of the literature. J Epidemiol Community Health 1986;40:30-6.

4. Terracini B, Pastore G, Segnan N. Association of father's occupation and cancer in children. Biol Res Pregnancy Perinatology $1983 ; 4: 40-5$.

5. Savitz DA, Chen J, Parental occupation and childhood cancer" review of epidemiologic studies. Environ Health Perspect 1990;88:325-37.

6. Spitz MR, Johnson CC. Neuroblastoma and paternal occupation: a case-control analysis. Am J Epidemiol 1985;121:924 9.

7. Nasca PC, Baptiste MS, MacCubbin PA, Metzger BB, Carlton $K$, Greenwald $P$, et al. An epidemiologic case-control study of central nervous system tumors in children and parental occupational exposures. Am J Epidemiol 1988;128:1256-65.

8. Wilkins JR III, Sinks TH Jr. Parental occupation and intracranial neoplasms of childhood: results of a case-control interview study. Am J Epidemiol 1990;132:275-92.

9. Johnson CC, Spitz MR. Childhood nervous system tumors: an assessment of risk associated with paternal occupations involving use, repair or manufacture of electrical and electronic equipment. Int J Epidemiol 1989;18:756-62.

10. Bunin GR, Ward E, Kramer S, Rhee CA, Meadows AT. Neuroblastoma and parental occupation. Am J Epidemiol 1990;131:776-80.

11. Wilkins JR III, Hundley VD: Paternal occupational exposure to electromagnetic fields and neuroblastoma in offspring. Am J Epidemiol 1990;131:995-1008.

12. Hsieh CC, Walker AM, Hoar SK. Grouping occupations according to carcinogenic potential: occupation clusters from an exposure linkage system. Am J Epidemiol 1983;117:575-89.

13. Hoar SK, Morrison AS, Cole P, Silverman DT. An occupation and exposure linkage system for the study of occupational carcinogenesis. J Occup Med 1980;22:722-6.

14. Wilkins JR III, Sinks TH, Jr. Parental occupation and brain tumors in offspring: results of a case-control study [abstract]. Am J Epidemiol 1988;128:912

15. Savitz DA. Overview of epidemiologic research on electric and magnetic fields and cancer. Am Ind Hyg Assoc J 1993; $54: 197-204$

16. Bowman JD, Garabrant DH, Sobel E, Peters JM. Exposures to extremely low frequency (ELF) electromagnetic fields in occupations with elevated leukemia rates. Appl Ind Hyg 1988;3: $189-94$.

17. Milham $\mathrm{S} \mathbf{J}$. Mortality from leukemia in workers exposed to electrical and magnetic fields [letter]. N Engl J Med 1982; $307: 249$

18. Loomis DP, Savitz DA. Mortality from brain cancer and leukaemia among electrical workers. Br J Ind Med 1990;47:633 8.

19. US Department of Commerce. Alphabetical index of industries and occupations: 1980 census of population. Washington (DC): US Government Printing Office, 1989.

20. Stuchly MA, Lecuyer DW. Exposure to electromagnetic fields in arc welding. Health Phys 1989;56:215-25.

21. Lemasters GK. Occupational exposures and effects on male and female reproduction. In: Rom WN, editor. Environmental and occupational medicine. Boston (MA): Little, Brown and Company, 1992:147-70.

22. Schlesselman JJ, Case-control studies: design, conduct, analysis. New York (NY): University Press, 1982. 
23. Robins J, Breslow N, Greenland S. Estimators of the MantelHaenszel variance consistent in both sparse data and largestrata limiting models. Biometrics 1986;42:311--23.

24. Cytel Software Corp. StatXact statistical software for nonparametric inference. Cambridge (MA): Cytel Software Corp, 1989.

25. Bracken TD. Exposure assessment for power frequency electric and magnetic fields. Am Ind Hyg Assoc J 1993;54:16577.

26. Weiss NS. Should we consider a subject's knowledge of the etiologic hypothesis in the analysis of case-control studies? [abstract]. Am J Epidemiol 1994;139:247-9.

27. Mitchell AA, Werler MM, Shapiro S. A response to the commentary "Should we consider a subject's knowledge of the etiologic hypothesis in the analysis of case-control studies?" [abstract]. Am J Epidemiol 1995;141:297-8.

28. Boyle CA, Brann EA, Selected Cancers Cooperative Study Group. Proxy respondents and the validity of occupational and other exposure data. Am J Epidemiol 1992;136:712-21.

29. Howe GR, Burch JD, Chiarelli AM, Risch HA, Choi BCK. An exploratory case-control study of brain tumors in children. Cancer Res 1989;49:4349-52.

30. Gold EB. Epidemiology of brain tumors. In: Lilienfeld AM, editor. Reviews in cancer epidemiology. New York (NY): Elsevier/North-Holland, 1980:245-92.

31. Gold E, Gordis L, Tonascia J, Szklo M. Risk factors for brain tumors in children. Am J Epidemiol 1979;109:309-19.

32. Rachootin P, Olsen J. The risk of infertility and delayed conception associated with exposures in the Danish workplace. J Occup Med 1983;25:394-402.

33. Mortensen JT. Risk for reduced sperm quality among metal workers, with special reference to welders. Scand J Work Environ Health 1988;14:27-30.

34. Bonde JP. Semen quality and sex hormones among mild steel and stainless steel welders: a cross-sectional study. $\mathrm{Br}$ J Ind Med 1990;47:508-14.

35. Wilson BW, Stevens RG, Anderson LE, editors. Extremely low frequency electromagnetic fields: the question of cancer. Columbus (OH): Battelle Press, 1990.

36. Guidotti TL, Lappi VG, Langard S. Hazards of welding technologies. In: Rom WN, editor. Environmental and occupational medicine. Boston (MA): Little, Brown and Company, 1992:831-41.

Received for publication: 14 August 1995 